\title{
A study of serum Cadmium and lead in Iraqi postmenopausal women with osteoporosis
}

\author{
Dr Zina Hasan Abdul-Qahar; MBChB, FICMS-Chemical Pathology. \\ Department of Biochemistry, College of Medicine/ University of Baghdad, Iraq
}

\begin{abstract}
Postmenopausal status is an independent risk factor for osteoporosis. Several studies have reported that heavy metals, including lead, mercury, cadmium, and arsenic, have harmful effects on bone. The aim of this study was to evaluate the effect of heavy metals, including Cadmium and Lead on osteoporosis in postmenopausal Iraqi women. This prospective study included a total of 70 postmenopausal women divided as 40patients with osteoporosis compared to 30 apparently healthy women as controls during 2011. Serum levels of Cadmium and Lead were measured using atomic absorption while serum Calcium, Phosphorus and Alkaline phosphatase were measured by spectrophotometry. The results showed that there was no significant difference between patients and controls regarding age, Body Mass Index, Calcium, Phosphorous, and Alkaline phosphatase. Serum levels of Cadmium and Lead were higher in patients compared to controls, $p<0.001$ and $p<0.01$ respectively. It is concluded that increased serum levels of cadmium and lead maybe associated with higher risk of osteoporosis in postmenopausal women.
\end{abstract}

Keywords: cadmium, lead, obesity, osteoporosis, postmenaopause

\section{Introduction}

Osteoporosis is a bone disease caused by decreased bone mineral density (BMD) and bone micro architecture deterioration. ${ }^{[1]}$ Osteoporosis definition reported by the World Health Organization (WHO) as a bone mineral density of 2.5 standard deviations or more below the mean peak bone mass (average of young, healthy adults) as measured by dual-energy X-ray absorptiometry (DEXA).$^{[2]}$

Primary osteoporosis could be either type 1 ; which is common in women after menopause called (postmenopausal osteoporosis), or type 2 that occurs after the age of 75 years and is seen in both sexes and is called (senile osteoporosis) being more common in women in a ratio of (2:1). As for secondary osteoporosis; it may occur at any age and affects both sexes equally. ${ }^{[2,3]}$

Cadmium is a pollutant that is mainly present in tobacco. Its threat to human health is caused by its long retention as it is not easily detoxified in human body or excreted by the renal system. ${ }^{[4,5]}$

In addition; Cadmium has an environmental hazard through exposure to fuel combustion, phosphate fertilizers, natural sources, iron and steel production, cement production, nonferrous metals production, and solid waste incineration. Some kinds of food like bread and vegetables also contribute to the cadmium intake in modern societies. ${ }^{[6]}$

Lead, at definite levels, is a poisonous substance to all living subjects. Different communities are exposed to lead from air and food in roughly equal proportions. Lead can reach humans via the food chain because airborne lead can be deposited on soil and water. Lead is considered as a neurotoxin that damages the nervous system causing brain disorders; it also has cumulative effects through deposition in both soft tissues and bones. ${ }^{[4,7]}$

Aim of this study was to evaluate the association between heavy metals, including Cadmium and Lead, with osteoporosis in postmenopausal Iraqi women comparing the results to non-osteoporotic postmenopausal control women.

\section{Materials \& Methods}

Since bone metabolic status is affected by variation in sex hormones levels; this prospective study included a total number of seventy postmenopausal women divided into two groups:

1. Fourty patients with osteoporosis were recruited from Rheumatology \& Rehabilitation outpatient clinic and were diagnosed by the rheumatologist using DEXA according to WHO diagnostic criteria. ${ }^{[2]}$

2. Thirty apparently healthy controls with matching age from relatives attending the health institutions.

Patients with a history of cardiac diseases, rheumatoid arthritis, diabetes mellitus, and smokers were excluded from the study.

Blood was withdrawn from all participants and the following parameters were measured in serum after centrifugation:

1. Cadmium and Lead using atomic absorption spectrophotometer.

2. Calcium and phosphorus levels were measured by colorimetric kit using spectrophotometer. 
3. Alkaline phosphatase enzyme was measured by kinetic method using UV spectrophotometer.

Weight and height were recorded for all study subjects using the same scale, and Body Mass Index (BMI) was calculated by the standard equation. ${ }^{[8]}$

\section{Statistical Analysis:}

The Statistical Package for Social Sciences-version 17 (SPSS-17) was used for data input and analysis. The results were reported as mean \pm standard deviation (mean $\pm \mathrm{SD}$ ). The student $\mathrm{t}$-test used to calculate the differences between any two means. Correlation coefficients were measured using Pearson's correlation coefficient (r). The criteria for statistical significance was determined at $\mathrm{P}$ value $<0.05$.

\section{Results}

The subjects' ages ranged from (45-65) years for both patients and controls. Table (1) shows the demographic characteristics of study subjects. Calculations of BMI showed that all study subjects were obese $\left(\mathrm{BMI} \geq 30 \mathrm{~kg} / \mathrm{m}^{2}\right)$; with a strong positive correlation between BMI and age $(\mathrm{r}=0.823, \mathrm{p}<0.05)$. There were no significant differences in age and BMI between means of osteoporotic patients and controls.

Table 1: demographic data of study subjects

\begin{tabular}{lcc}
\hline & Patients(No.=40) & Control(No.=30) \\
\cline { 2 - 3 } Variable & Mean \pm SD $\dagger$ & Mean \pm SD \\
\hline Age $($ years) & $62 \pm 5.732$ & $59 \pm 5.583$ \\
BMI* $(\mathrm{kg} / \mathrm{m} 2)$ & $32.5 \pm 3.27$ & $30.9 \pm 4.98$ \\
\hline *BMI; body mass index & & \\
$\dagger$ SD; standard deviation & &
\end{tabular}

Serum Calcium, Phosphorus, and Alkaline Phosphatase measurements were within normal values for all study subjects; there was no significant difference between patients and controls (Table 2).

Table 2: Mean \pm standard deviation of serum calcium, phosphorous, alkaline phosphatase, lead, and cadmium in patients and controls

\begin{tabular}{lccc}
\hline & Patients & Control & P value \\
\cline { 2 - 3 } Variable & Mean \pm SD* & Mean \pm SD & $>0.05$ \\
$\mathrm{Ca}^{++}(\mathrm{mmol} / \mathrm{L})$ & $2.26 \pm 0.168$ & $2.087 \pm 0.135$ & $>0.05$ \\
$\mathrm{PO}_{4}(\mathrm{mmol} / \mathrm{L})$ & $1.187 \pm 0.21$ & $1.127 \pm 0.187$ & $>0.05$ \\
$\mathrm{ALP}(\mathrm{U} / \mathrm{L})$ & $66.27 \pm 11.26$ & $68.27 \pm 11.732$ & $<0.001$ \\
$\mathrm{~Pb}(\mathrm{ng} / \mathrm{L})$ & $0.174 \pm 0.014$ & $0.9 \pm 0.06$ & $<0.01$ \\
$\mathrm{Cd}(\mathrm{ng} / \mathrm{L})$ & $0.172 \pm 0.012$ & $0.032 \pm 0.05$ & \\
\hline *SD; standard deviation & & &
\end{tabular}

Many correlations were observed in this study. In patients; age had a negative correlation with calcium ( $\mathrm{r}=-$ $0.53, \mathrm{p}=0.017)$ while Calcium had a negative correlation with alkaline phosphatase $(\mathrm{r}=-0.054, \mathrm{p}=0.014)$. Also there was a strong positive correlation between cadmium and lead $(\mathrm{r}=0.85, \mathrm{p}<0.05)$.

Upon measuring cadmium and lead in study subjects; there was a significant difference between patients and controls. Serum Cadmium and Lead levels were higher in osteoporotic patients compared to controls; ( $p$ value $<0.01$ and $<0.001$ ) respectively (table 2 ).

\section{Discussion}

Osteoporosis is a major public health problem most commonly affecting postmenopausal women and is characterized by excessive skeletal fragility which is attributable to intrinsic skeletal factors such as low bone mass and sluggish or insufficient repair of micro trauma to bones. ${ }^{[9,10]}$

All our study subjects were found to be obese showing increased BMI with increased age in a linear relationship; which agrees with previous studies. ${ }^{[11,12,13]}$ The economic growth of the Gulf region has resulted in increases in dietary health problems and related diseases especially obesity in Asian women. This was first noted in developed nations, but has rapidly spread to developing countries in the past few years. ${ }^{[12,14]}$ All adults in the Arab Gulf area live sedentary life styles and occasionally participate in sports. ${ }^{[15]}$ Arabian women specifically show low physical activities mostly due to strong socio-cultural traditions that represent an obstacle for involvement in sporting venues. ${ }^{[16]}$ The hot weather and sand storms largely discourage outdoor activities while indoor activities (such as TV watching) and socializing frequently involve eating and snacking; subsequently resulting in obesity. ${ }^{[12]}$

Obesity and osteoporosis share several common genetic and environmental factors. Also normal aging is associated with both a high incidence of osteoporosis and adiposity. ${ }^{[9,17]}$ This study showed no relation between obesity and osteoporosis; in contrast to other studies. ${ }^{[9,17,18]}$ Rayalam and colleagues discovered through a clinical trial that the differentiation of precursor mesenchymal stem cells into adipocytes dominates 
over the differentiation into osteoblasts; thus explaining the inverse relationship between adipocytes and osteoblasts in the aging population. ${ }^{[19]}$

The homeostasis of calcium and phosphorpus is maintained in serum regardless of their bone storage and these parameters are not expected to vary significantly in patients with osteoporosis and controls since bone thinning disease as osteoporosis does not affect calcium and phosphorous metabolism and diagnosis of osteoporosis would not depend on any change in serum calcium, phosphorous, or alkaline phosphatase levels ${ }^{[20,21]}$; which agrees with the results of this study.

The present study showed that within normal ranges; calcium correlated negatively with increased age and with ALP; the relatively low serum Ca and the high ALP indicate that geriatric patients especially residents at home may suffer from subclinical osteomalacia. ${ }^{[22]}$ It is known that obese patients have abnormal calcium metabolism compared with the non-obese controls. ${ }^{[23]}$ Also osteoporosis and age related alterations in bone metabolism are common clinical conditions in Asia since the Asian diet is low in calcium content. ${ }^{[9,24]}$ Gallagher and colleagues have demonstrated that intestinal calcium absorption decreased significantly with aging in patients with postmenopausal osteoporosis. ${ }^{[25]}$ For this reason it is recommended that supplementing the diet of postmenopausal women with calcium is effective in preventing height and bone loss to avoid public health impact of decreased calcium especially in Asian women. ${ }^{[24]}$

In this study there was an obvious increase in serum levels of cadmium and lead in osteoporotic patients compared to controls; this agrees with previous studies done in Asia ${ }^{[26-28]}$, Europe ${ }^{[5,29-30]}$, and America ${ }^{[31-3]}$. These results were independent of tobacco smoking, which is both an important source of Cadmium and a risk factor for osteoporosis. ${ }^{[30]}$

Several studies tried to clarify the mechanisms for Cadmium-induced osteoporosis. Experimental data demonstrate a direct effect of Cadmium on bone both ways: with decreased bone formation and increased bone resorption. ${ }^{[33]}$ Osteoblasts exposed to high Cadmium levels had decreased their bone-forming activity and secreted prostaglandin $\mathrm{E}_{2}$, which, in turn, can increase the formation and activity of osteoclasts. ${ }^{[2,33]}$ Other studies also supported that Cadmium had induced increased bone resorption more than its effect on bone formation hence lowering bone mineral density especially in older people. ${ }^{[5,29,33-35]}$

About $90 \%$ of all the body content of lead is localized to bone by replacement of calcium, so even a physiological increase of skeletal turnover, as in menopause, would affect the levels of lead in blood. ${ }^{[31]}$ Previous studies indicated that lead may have effects on bone turnover either directly on osteoblast and osteoclast function, or indirectly via kidney diseases, or both. ${ }^{[28,36]}$

Since stored lead in bones has a long half-life that may reach years; skeletal lead stores may be a source of endogenous lead exposure during periods of increased bone demineralization, such as menopause ${ }^{[4,31]}$, and the increased bone resorption, as occurs postmenopausally because of decreased estrogen production, results in release of bone lead stores into blood. ${ }^{[31,36]}$ Thus attention to factors that affect postmenopausal bone loss may lessen or at least control blood lead levels. ${ }^{[31]}$

Although the overall role of cadmium and lead in the etiology of osteoporosis is limited but in view of the high prevalence of this disease, even a little effect is important at the population level since everyone has lifelong exposure to these potential carcinogens ${ }^{[37,38]}$; especially in Asian diet ${ }^{[39]}$, this emphasizes the importance of efforts needed to reduce cadmium and lead pollution of the environment.

\section{Conclusion}

In conclusion, although it is clear that genetic, hormonal, and personal factors have a major role for the development of postmenopausal osteoporosis and that promoting regular exercise is an effective preventive measure; other environmental factors also may play an important role such as Cadmium and Lead; that is why efforts should be taken to reduce Cadmium exposure and identify modifiable factors that prevent bone lead release.

Further studies are necessary to explore the etiologic association between cadmium and osteoporosis and to further investigate whether a causative association exists between lead exposure and postmenopausal osteoporosis.

To summarize, this study found a relationship between high serum cadmium and lead levels with osteoporosis in postmenopausal Iraqi women so it strengthens previous evidence that environmental cadmium and lead exposure may affect bone metabolic status and bone metabolic diseases such as osteoporosis.

\section{Acknowledgement}

The author acknowledges the important contributions of assistant lecturer Rana A. Hamdi (University of Baghdad, College of Medicine/ Biochemistry Department) and assistant lecturer Ahmed A. Abdul-Hameed (University of Baghdad, College of Medicine/IT department), both of whom provided guidance and invaluable comments on this paper. 


\section{References}

[1]. Alldredge BK; Kimble K, Anne M, Lloyd Y, Kradjan WA; GuglielmoBJ. Applied therapeutics: the clinical use of drugs. Philadelphia: Wolters Kluwer Health/Lippincott Williams \& Wilkins. 2009; 101-3. ISBN 0-7817-6555-2.

[2]. World Health Organization (WHO). 1994 Assessment of fracture risk and its application to screening for postmenopausal osteoporosis: Report of a WHO study group in Geneva, Switzerland: WHO Technical Report Series; 1994; 843: 1-129. PMID 7941614.

[3]. Lu Y, Genant HK, Shepherd J, Zhao S, Mathur A, Fuerst TP, et al. Classification of Osteoporosis Based on Bone Mineral Densities. J Bone Miner Res 2001; 16(5): 901-910. doi: 10.1359/jbmr.2001.16.5.901.

[4]. Järup L. Hazards of heavy metal contamination. Br Med Bull 2003; 68: 167-182.

[5]. Alfvén T, Järup L, Elinder CG. Cadmium and Lead in Blood in Relation to Low Bone Mineral Density and Tubular Proteinuria. Environ Health Perspect 2002; 110(7): 699-702. [PubMed]

[6]. Morrow H. Cadmium and Cadmium Alloys. Kirk-Othmer Encyclopedia of Chemical Technology 2010; 1-36.

[7]. Osofskydvm A, Peter Lh, Hosgoodbvs G, Tullydvm Tn. Determination of Normal Blood Concentrations of Lead, Zinc, Copper, and Iron in Hispaniolan Amazon Parrots (Amazona ventralis). J Avian Med Surg 2001; 15(1):31-36.

[8]. Flier JS, Maratos-Flier E. Obesity. In: Kasper DL, editor. Harrisons's principles of Internal Medicine, $16^{\text {th }}$ ed.USA: McGraw-Hill Companies; 2005; 64:422-430.

[9]. Zhao LJ, Jiang H, Papasian CJ, Maulik D, Drees B, Hamilton J, et al. Correlation of Obesity and Osteoporosis: Effect of Fat Mass on the Determination of Osteoporosis. J Bone Miner Res 2008 Jan; 23(1): 17-29.

[10]. Kalichman L, Malkin I, Bigman G, Matias R, Seibel MJ, Kobyliansky E. Age-Related Changes in Bone-Strength-Associated Geometry Indices in Naive Human Population. Anat Rec 2008 Jul; 291(7): 835-844.

[11]. Elia M. Obesity in the Elderly; North American Association for the Study of Obesity (NAASO). Dietary Patterns for Weight Management and Health 2001 Nov; 9(S11): 224S-248S.

[12]. Ng SW, Zaghloul S, Ali HI, Harrison G, Popkin BM. The prevalence and trends of overweight, obesity and nutrition-related noncommunicable diseases in the Arabian Gulf States. International Association for the Study of Obesity. Obes Rev 2011Jan; 12(1): 113.

[13]. Baumgarter RN, Heymsfield SB, Roche AF. Human body composition and the epidemiology of chronic disease. Obes Res 1995; 3 : 73-95. [PubMed]

[14]. Popkin BM. Global nutrition dynamics: the world is shifting rapidly toward a diet linked with noncommunicable diseases. Am J Clin Nutr 2006; 84: 289-298. [PubMed]

[15]. Mabry RM, Reeves MM, Eakin EG, Owen N. Evidence of physical activity participation among men and women in the countries of the Gulf Cooperation Council: a review. Obes Rev 2009; doi: 10.1111/j.1467-789X.2009.00655.x

[16]. Berger G, Peerson A. Giving young Emirati women a voice: participatory action research on physical activity. Health Place 2009; 15: 117-124. [PubMed]

[17]. Rosen CJ, Bouxsein ML. 2006 Mechanisms of Disease: Is osteoporosis the obesity of bone? Nat Clin Pract Rheumatol 2006; 2: 3543. [PubMed]

[18]. Greco EA, Fornari R, Rossi F, Santiemma V, Prossomariti G, Annoscia C, et al. Is obesity protective for osteoporosis? Evaluation of bone mineral density in individuals with high body mass index. Int J Clin Pract 2010 May; 64(6): 817-820.

[19]. Rayalam S, Della-Fera MA, Baile AC. Synergism between resveratrol and other phytochemicals: Implications for obesity and osteoporosis. Mol Nutr Food Res 2011 Aug; 55(8): 1177-1185.

[20]. Jayaram N, Bijoor AR, Rajagopalan N, Venkatesh T. the value of serum and urinary n-Telopeptide in the diagnosis of osteoporosis. I J O 2002; 36(2): 9.

[21]. Simon AJ. Osteoporosis. Rheum Dis Clin N Am 2007; 33: 149-176.

[22]. Lamberg-Allardt C. The relationship between serum 25-hydroxy-vitamin D levels and other variables related to calcium and phosphorus metabolism in the elderly. Acta Endocrinol 1984 Jan; 105(1): 139-144.

[23]. Hamoui N, Anthone G, Crookes PF. Calcium Metabolism in the Morbidly Obese. Obesity Surgery 2004 Jan; 14(1): 9-12.

[24]. Lau EMC, Woo J, Lam V, Hong A. Milk Supplementation of the Diet of Postmenopausal Chinese Women on a Low Calcium Intake Retards Bone Loss. J Bone Miner Res 2001 Sep; 16(9): 1704-1709.

[25]. GallagherJC, Lawrence Riggs B, Eisman J, Hamstra A, Arnaud SB, Deluca HF. Intestinal Calcium Absorption and Serum Vitamin D Metabolites in Normal Subjects and Osteoporotic Patients. J Clin Invest. 1979 Sep; 64(3): 729-736. doi: 10.1172/JCI109516. PMCID: PMC372174

[26]. Honda R, Tsuritani I, Noborisaka Y, Suzuki H, Ishizaki M, Yamada Y. Urinary cadmium excretion is correlated with calcaneal bone mass in Japanese women living in an urban area. Environ Res. 2003;91(2):63-70. [PubMed]

[27]. Wang H, Zhu G, Shi Y, Weng S, Jin T, Kong Q, et al. Influence of environmental cadmium exposure on forearm bone density. J Bone Miner Res. 2003;18(3):553-560. [PubMed]

[28]. Sun Y, Sun D, Zhou Z, Zhu G, Zhang H, Chang X, et al. Osteoporosis in a Chinese population due to occupational exposure to lead. Am J Ind Med 2008 Jun; 51(6): 436-442.

[29]. Åkesson A, Lundh T, Vahter M, Bjellerup P, Lidfeldt J, Nerbrand C, et al. Tubular and glomerular kidney effects in Swedish women with low environmental cadmium exposure. Environ Health Perspect. 2005;113:1627-1631. [PubMed]

[30]. Engström A, Michaëlsson K, Suwazono Y, Wolk A, Vahter M, Åkesson A. Long-term cadmium exposure and the association with bone mineral density and fractures in a population-based study among women. J Bone Miner Res 2011 Mar; 26(3): 486-495.

[31]. Nash D, Magder LS, Sherwin R, Rubin RJ, Silbergeld EK. Bone density-related predictors of blood lead level among peri- and postmenopausal women in the United States: the Third National Health and Nutrition Examination Survey, 1988-1994. Am J Epidemiol. 2004;160(9):901-911. [PubMed]

[32]. Gallagher CM, Kovach JS, Meliker JR. Urinary cadmium and osteoporosis in U.S. Women $>$ or $=50$ years of age: NHANES 19881994 and 1999-2004. Environ Health Perspect. 2008; 116: 1338-1343.

[33]. Bhattacharyya MH. Cadmium osteotoxicity in experimental animals: mechanisms and relationship to human exposures. Toxicol Appl Pharmacol. 2009; 238: 258-265.

[34]. Nawrot T, Geusens P, Nulens T, Nemery B. Occupational cadmium exposure and calcium excretion, bone density and osteoporosis in men. J Bone Miner Res. 2010; 25: 1441-1445.

[35]. Schutte R, Nawrot TS, Richart T, et al. Bone resorption and environmental exposure to cadmium in women: a population study. Environ Health Perspect. 2008; 116: 777-783.

[36]. Korrick SA, Schwartz J, Tsaih SW, Hunter DJ, Aro A, Rosner B. Correlates of Bone and Blood Lead Levels among Middle-aged and Elderly Women. Am J Epidemiol 2002; 156(4): 335-343. 
[37]. Lin YS, Caffrey JL, Lin JW, Bayliss D, Faramawi MF, Bateson TF, et al. Increased Risk of Cancer Mortality Associated with Cadmium Exposures in Older Americans with Low Zinc Intake. J Toxicol Environ Health A 2013 Jan; 76(1): 1-15.

[38]. Hartwig A. Cadmium and Cancer. Sigel A, Sigel H, Sigel KO, editors. Cadmium : from toxicity to essentiality. Met Ions Life Sci 2013; 11: 491-507. DOI: 10.1007/978-94-007-5179-8 15.

[39]. Park S\& Lee BK. Strong positive association of traditional Asian-style diets with blood cadmium and lead levels in the Korean adult population. Int J Environ Health Res 2013 Feb. Available from: http://dx.doi.org/10.1080/09603123.2013.769204. 